Revista de Filología Románica

ISSN: 0212-999X

http://dx.doi.org/10.5209/RFRM.58354

\title{
Dos imaginarios literarios de la niñez y la vejez: Joseph Zobel y Gabriel García Márquez
}

\author{
Martha Asunción Alonso ${ }^{1}$
}

Recibido: 20 de febrero de 2017 / Aceptado: 2 de julio de 2017

Resumen. En 1974, Joseph Zobel (Martinica, 1915-Francia, 2006) publicó la novela La Rue Cases-Nègres, pieza maestra de la denominada "literatura de la Negritud" en el Caribe francófono. En 1968, en similares latitudes tropicales, Gabriel García Márquez había escrito el cuento Un señor muy viejo con unas alas muy grandes.

Nuestro objetivo es analizar, a lo largo de las siguientes páginas, cómo el relato de Márquez -notable ejemplo de la corriente literaria del "Realismo Mágico"- prefigura un imaginario de la niñez/vejez que redescubrimos seis años después en la obra de Zobel.

Partiendo de las relaciones entre los personajes de los hijos y sus padres ausentes, estudiaremos las dinámicas de sustitución y simbiosis que adoptan los nietos para con los abuelos, por una parte; y la metamorfosis de estos últimos en seniles, decrépitos y ambivalentes ángeles guardianes.

Palabras clave: Caribe; Zobel; Márquez; Niñez; Vejez; Ángeles.

\section{[en] The poetics of childhood and old age in two short stories by Joseph Zobel and Gabriel García Márquez}

\begin{abstract}
In 1974, Joseph Zobel (Martinique, 1915-France, 2006) published the novel La Rue Cases-Nègres, a masterpiece of the so-called "literature of Negritude" in the french-speaking West Indies. In 1968, the colombian Nobel Prize in literature Gabriel García Márquez published the short story Un señor muy viejo con unas alas muy grandes.

The aim of this article is to analyze how Márquez's text introduces in that short story an imaginary of the childhood / old age that can be found six years later in Zobel's book.

We will study the symbiotic relations that the absence of parents establishes between the characters of the grandchildren and those of the grandparents in these two texts. Moreover, we will try to show how these old characters can metamorphose, despite their senility and therefore their poetic ambivalence, into guardian angels.
\end{abstract}

Keywords: Caribbean; Zobel; Márquez; Childhood; Old age; Angels.

Cómo citar: Alonso, M.A. (2017). Dos imaginarios literarios de la niñez y la vejez: Joseph Zobel y Gabriel García Márquez, en Revista de Filología Románica 34.2, 337-346.

\footnotetext{
Profesora de la Academia de Amiens Doctora en Filología Francesa por la UCM marthasun@gmail.com
} 
...y nunca se supo si fue por ángel o por viejo que terminó comiendo nada más que papillas de berenjena.

Gabriel García Márquez.

En 1974, el autor martiniqués Joseph Zobel (1915-2006) publicó la internacionalmente traducida y celebrada novela La Rue Cases-Nègres, pieza maestra de la denominada "literatura de la Negritud" en el espacio del Caribe francófono².

En 1968, tan sólo seis años antes y en similares latitudes tropicales, Gabriel García Márquez (1927-2014) había escrito el cuento Un señor muy viejo con unas alas muy grandes. Por su parte, este relato, como tantas otras obras universales del genio colombiano, se considera un claro exponente de la corriente literaria que, mediante la "adivinación poética" o "la negación poética de la realidad", se esfuerza en desentrañar la esencia del "hombre como misterio" (ÚSLAR PIETRI 1948: 287). Nos referimos, claro está, al "Realismo Mágico". O, por decirlo en palabras del escritor cubano Alejo Carpentier (1904-1980), enamorado también del vasto continente americano y sus islas todas, nos referimos a la corriente literaria de "lo real maravilloso":

...esa inesperada alteración de la realidad, una revelación privilegiada, una iluminación inhabitual, una fe creadora de cuanto necesitamos para vivir en libertad; una búsqueda, una tarea de otras dimensiones de la realidad, sueño y ejecución, ocurrencia y presencia (CARPENTIER 2004: 11).

Más allá de las diferencias inherentes a sus respectivos géneros narrativos, las lenguas y las preferencias estilísticas de los autores, las dos historias que hoy centran nuestra atención -la de Zobel y la de Márquez-, presentan notables similitudes. En especial, dichas semejanzas nos parecen concentrarse en el nivel simbólico, esto es, en lo que se refiere a sus imaginarios sobre dos períodos privilegiados de la existencia del ser humano: la niñez y la vejez. Ambas etapas vitales se configuran en ambos relatos en torno a los preceptos -no tan alejados el uno del otro como quizás pudiera parecer en un primer momento- de la Negritud y el Realismo Mágico. Trataremos a continuación de ver cómo y por qué.

Para empezar, tanto en La Rue... como en Un señor muy viejo..., observamos la división del elenco de personajes en dos universos tan distintos como complementarios: niños, preadolescentes y adolescentes, por un lado; adultos, ancianos y muy ancianos, por otro lado. Ambos relatos ofrecen el retrato de sociedades polarizadas en los dos extremos vitales occidentalmente considerados. A saber: la vejez y la moderna idea de niñez (ARIÈS, 1960). Por decirlo de otro modo, nos adentramos en la contemplación del retrato de dos sociedades que, como se deducirá de los puntos siguientes, "tienen los ancianos que merecen", si se nos permite la paráfrasis española de Jean Delumeau en su prólogo a la Histoire de la vieillesse en Occident, de Georges Minois (1987).

En el cuento de Márquez, contamos entre los personajes ligados a la vejez, efectiva o potencial, a Pelayo (padre del bebé), a Elisenda (madre del bebé), al Padre Gon-

En efecto, esta obra de Zobel vehicula los preceptos fundamentales de la Negritud en tanto que movimiento no sólo literario, sino también político-social. La Negritud, en suma, como bien la definió su compatriota, el poeta Aimé Césaire : “...la Négritude a été une révolte contre ce que j’appellerai le réductionisme européen” (1955: 84). 
zaga y, por supuesto, al ángel anciano caído del cielo, con sus harapos de mendigo y sus grandes alas.

En la novela de Zobel, contamos entre los personajes ligados a la vejez a M'man Tine / Amantine (abuela del niño narrador), a Mam'zelle 3 Apolline (vecina soltera), M. Synphor y Mam'zelle Francette (padres de Orélie), M. Asselin y M. Médouze (también vecinos ancianos del poblado, solitarios, solteros o tal vez viudos). Los niños de La Rue... son el propio narrador, cuyo nombre ignoramos; Orélie y su hermana Tortilla, Paul, Romane, Gesner, Soumane, Victorina, Casimir y Héctor, entre otros. Los nombres de esos otros, a decir verdad, apenas si resultan relevantes en este caso. Lo importante aquí es la constitución gregaria de la infancia, es decir, las nociones de unidad y colectividad como bases del grupo de niños habitantes de la calle Cases-Nègres. No en vano, el narrador infantil se refiere a ese grupo como "la bande" (ZOBEL 1974: 20) y se confiesa incapaz de ofrecer al lector un recuento o una descripción exactos de sus integrantes:

Combien sommes-nous ? Je ne crois pas que nous ayons jamais compté. Nous remarquons bien lorsqu'il en manque : chacun a ses préférés et le signale s'il n'est pas là ; et nous sentons aussi bien quand nous sommes au grand complet (ZOBEL 1974: 20).

La construcción narratológica de los mundos de la niñez y la vejez orbita, como no podía ser de otro modo, bien cerca de la noción derrideana de "différance" (DERRIDA 1967): alteridad anárquica, de imposible mímesis objetiva. Así, para representar la gran diferencia -hecha de piel, de edad, de idioma, de paisajes, de origen...: de tantas pequeñas diferencias-, tanto Zobel como Márquez recurren a esa "iluminación inhabitual" de la que nos hablaba Carpentier. Una iluminación que dirige sus haces, primeramente, sobre la inefable y fascinadora diferencia de los cuerpos que todo lo han vivido: los cuerpos de los ancianos.

La mirada infantil, tan sincera como rica en dioptrías fantásticas, resulta imprescindible a la hora de visibilizar -dignificándola- tan compleja corporalidad. El narrador protagonista de La Rue..., en ese sentido, no escatima en minuciosas descripciones del cuerpo de la abuela, marcado por largos años de malos tratos, partos, privaciones y duros trabajos al sol en las plantaciones de caña de azúcar. La mirada del niño, en realidad, no se limita a describir el cuerpo exangüe de la mujer sexagenaria que con él ejerce de madre. Se trata, pues, retomando las palabras de Claudia Amigo en su reflexión sobre las escrituras de la infancia en las literaturas caribeñas, de "inscribir, mostrar y recrear una cicatriz" (2013). Así las cosas, la prosopopeya vira pronto hacia la oda, pues la mirada del niño, además de contarla, canta la maravilla del amado cuerpo viejo:

Par la fenêtre de la pièce, la lumière du jour se renverse sur son dos, qui montre une peau fanée à travers les déchirures d'une vieille robe devenue ajourée comme un filet, et qu'elle rêvet pour dormir (ZOBEL 1974: 17).

Nótese, por cierto, que la poética zobeliana de la vejez no se sustenta sobre imágenes masculinas en exclusiva, como a menudo pueda suceder y ya señalara, en

Man' / Mam'zelle: tratamientos de Madame / Mademoiselle, pronunciados a la criolla (Guadalupe, Guyana y Martinica). 
1970, Simone de Beauvoir en su ensayo La vieillesse: "le discours tenu ordinairement sur les vieillards les imagine au masculin" (1970: 93).

En el relato de Márquez, la óptica infantil impregna con sutilidad y eficacia la perspectiva omnisciente del narrador en tercera persona. Se nos presenta al ángel anciano, desde su primera bizarra aparición, indisolublemente asociado al hijo recién nacido de Pelayo y Elisenda. Ambos cuerpos parecen así definirse mutuamente por antítesis e in absentia. La sola mención del bebé enfermo basta para proyectar su imagen mental en el lector, que inmediatamente después debe contraponerla a la insólita visión del ángel anciano:

Asustado por aquella pesadilla, Pelayo corrió en busca de Elisenda, su mujer, que estaba poniéndole compresas al niño enfermo, y la llevó hasta el fondo del patio. Ambos observaron el cuerpo caído con un callado estupor. Estaba vestido como un trapero. Le quedaban apenas unas hilachas descoloridas en el cráneo pelado y muy pocos dientes en la boca, y su lastimosa condición de bisabuelo ensopado lo había desprovisto de toda grandeza. Sus alas de gallinazo grande, sucias y medio desplumadas, estaban encalladas para siempre en el lodazal (GARCÍA MÁRQUEZ 2014: 100).

La indigencia vestimentaria, tanto en el cuento de Márquez como en la novela de Zobel, sustenta la honda comunión entre niños y ancianos. El motivo de la desnudez o la semidesnudez iguala a todos estos personajes en su humanidad, revistiendo con la nobleza de lo puro sus cuerpos sin artificios. Los personajes de mayor edad, al igual que los más jóvenes, carecen aquí de instintos y comportamientos sexuales. La rotunda sinceridad de su desabrigo nos remite a los hitos excepcionales de la existencia humana: el nacimiento y el fallecimiento. Ambos acontecimientos, alfa y omega del ciclo vital, están desprovistos por definición de los convencionalismos, trampantojos y demás máscaras que rigen el baile mundano en sociedad durante la edad adulta. Se comprende, por lo tanto, el comentado leitmotiv del desnudismo.

Ya hemos mostrado, algunas unas líneas más arriba, cómo los maltrechos vestidos de Man'Tine -en el texto de Zobel- no alcanzan a disimular la desnudez de su cuerpo, hermoso y sin embargo carente de connotaciones eróticas. También venimos considerando cómo -en el texto de Márquez- la aparición del ángel anciano -ente sexuado pero no sexual- se caracteriza por la exposición casi cruel de su fragilidad física. Esta exhibición del cuerpo sin defensas, débil, caído del cielo, traduce la imagen del organismo blando del infante, recién expulsado del paraíso irrecuperable que fue el vientre materno y arrojado sin remedio al "áspero mundo" (GONZÁLEZ 1956).

A veces, sólo a veces, ese fatigoso mundo descansa y permite algunas caricias: "Quand la tournée avait été sans incident ni malheur, le soir arrivait, souriant de tendresse" (ZOBEL 1974: 10). Otras noches, por el contrario, el mundo gira con su más lúgubre gesto. Despiadado, su naturaleza inclemente y colosal parece acrecentarse en la blandura de los pequeños cuerpos sin armaduras que libres lo habitan. Es el caso de la banda de niños, hijos de esclavos, que viven en la Rue Case-Nègres. Recorren los caminos y bosques ruidosos, descalzos, lastimosamente vestidos con más agujeros que tela, sin prejuicios ni relojes ni reglas, despeinados, hambrientos... Animalizados: 
Si nous étions tous nus !

-Moi aussi, j’aimerais mieux être nu...

-Moi aussi ! [...]

-Eh bé ! propose hardiment Romane, dès ce soir, nous allons demander à nos parents de nous laisser tous nus (ZOBEL 1974: 36).

Una de las muchachas más mayores de la banda de amigos, Tortilla, comienza a sentir la embestida del pudor. Sin duda, este personaje pronto dejará atrás las soleadas orillas de la infancia para introducirse como mujer en el misterioso jardín minado de la edad adulta: "Mais personne d'entre nous ne savait ce que M. Saint-Louis cultivait dans son jardin..." (ZOBEL 1974: 50). Por esa razón, la pre-púber Tortilla advierte al resto de que tales pueriles deseos de desnudez eterna son imposibles. Socialmente inaceptables, por contravenir las reglas, entre otras, de la moral cristiana: "Eh bé! s'écrie-t-elle, en se cambrant brusquement et en portant la main sous mon ventre, ton Bon Ange, c'est là. Voilà pourquoi on ne reste pas nu!" (ZOBEL 1974: 37).

Nueva subversión-perversión, por parte del martiniqués en esta ocasión: el sexo masculino y, por extensión, el deseo sensual se asimilan irónicamente con el ángel de la guarda. Lo que nos trae de regreso al texto de Márquez. En él, es precisamente otra mujer, aunque de mayor edad, quien identifica, sin tardar y sin rastro alguno de extrañeza, al alado recién llegado como un ángel. La sabiduría de la mirada inocente, libre de prejuicios, por lo tanto, queda definida en términos cualitativos más que cuantitativos. La hermosura niega ser una cuestión de años vividos, sino de años aprendidos y de intuición, don prominentemente femenino:

Sin embargo, llamaron para que lo viera a una vecina que sabía todas las cosas de la vida y la muerte, y a ella le bastó con una mirada para sacarlos del error. - Es un ángel -les dijo-. Seguro que venía por el niño, pero el pobre está tan viejo que lo ha tumbado la lluvia (GARCÍA MÁRQUEZ 2014: 100).

La iconografía tradicional del ángel cristiano de la guarda en tanto que ser genéricamente ambiguo y de aspecto juvenil se halla subvertida, por no decir pervertida, en el imaginario literario de Márquez. La criatura celestial hipotéticamente protectora del hijo de Pelayo y Elisenda, resulta ser un serafín senior, si se nos permite la expresión. Evoluciona marcha atrás desde las categorías de "bisabuelo ensopado" (vide supra) y "moribundo sin dueño" al título de "buitre senil". Es, a fin de cuentas, una de las "muchas atracciones de ferias errantes del Caribe".

La mención explícita del espacio caribeño en el cuento del colombiano no nos parece, en absoluto, arbitraria. Más aún cuando no se produce de forma aislada. Leemos asimismo que "vinieron curiosos hasta de la Martinica" en peregrinación para ver y pedir milagros al decrépito ángel cautivo en el patio, entre matojos y gallinas, de Pelayo y Elisenda. Cabe pensar que el autor de La Rue... sintió desde su Martinica natal curiosidad por el relato de Gabriel García Márquez. Y lo leyó. Al igual que las obras del colombiano constituyeron lecturas de primer orden para otros narradores francófonos criollos cercanos a Zobel, por ejemplo, la guadalupeña Maryse Condé, que suele citarlo en sus entrevistas como autor de referencia (PFAFF 1996: 46).

En cualquier caso, no son infrecuentes las conexiones de este orden entre los imaginarios postcoloniales caribeños y americanos. Todo ellos se encuentran regidos de preferencia por el sincretismo religioso-espiritual y la hibridación creativa del 
rompecabezas de la realidad en todos sus niveles: folclórico, simbólico, lingüístico, musical... En esta mixtura, en definitiva, residiría la esencia de la "West Indian Identity" (PFAFF 1996: 45) que tan a menudo ha sido objeto de estudios postcoloniales en torno a las problemáticas de la creolidad, los criollismos, la negritud, la alineación, la aculturación, las independencias, el mestizaje, etc.

Los ángeles, en resumen, pueden perfectamente ser ancianos en el imaginario caribeño. Muy concretamente, en el imaginario zobeliano, caracterizado por cierta tendencia a la "métamorphose du réel" (JULIEN, 1987). De ahí su erudición en lo que se refiere a los enigmas del corazón humano, la vida y la muerte. Pueden, además, presentar con naturalidad otro tipo de rasgos constitutivos que redunden en las ideas de diferencia y ambigüedad; características, por decirlo de otro modo, más bien propias de criaturas fantásticas de la cultura popular de aquellas latitudes u oralitura (BERNABÉ, CHAMOISEAU \& CONFIANT 1993). Presencias a medio camino entre lo benéfico y lo maléfico, capaces de infundir, según las ocasiones, tanto temor como amor. Estamos pensando en seres de leyenda, como el temido soukougnam de las Antillas francesas o chupacabras en Colombia, por citar un único ejemplo, no tan lejano: pues, ¿qué son nuestros coco, gamusinos, hombre del saco, etc. sino versiones ibéricas de idénticos miedos infantiles -humanos- simbólicamente sublimados?

Por todo lo dicho, en estos ángeles ambivalentes resuenan obligadamente la voz de los abuelos. Padres de los padres ausentes que terminan por asumir la responsabilidad de la protección, la educación, la manutención y la crianza, a fin de cuentas, de sus nietos. Sin ellos, estos niños quedarían huérfanos, hayan realmente muerto o no sus respectivos progenitores. Los ancianos remedian esa potencial orfandad y se erigen en ángeles guardianes. Tratan estos abuelos -de sangre o adopción- de acariciar y castigar a partes iguales. No siempre logran, claro está, el milagro del equilibrio. La rabiosa y dolorida reacción del ángel anciano del cuento de Márquez ante las crueldades de los peregrinos y vecinos puede ejemplificar con bastante claridad este punto. Al igual que la desmesura de las penitencias que la vieja Man'Tine impone a su nieto díscolo por las noches en la novela de Zobel:

-Pardon, m'man- fais-je.

-Lève-toi, mauvais garnement !

Mes genoux blessés ont saigné, et le sang coagulé les a soudés au sol si fort que c'est en étouffant un cri de douleur que je les ai décollés (ZOBEL 1974: 45).

Los abuelos-ángeles, aunque en ocasionen alcen la voz y la mano, mayoritariamente son sustento. En el texto de Márquez, la llegada del ángel de la senectud desencadenará mejorías progresivas en la salud del bebé de Pelayo y Elisenda. La curación y el crecimiento del niño influirá, de modo inversamente proporcional, en el deterioro del ángel anciano: "Ambos contrajeron la varicela al mismo tiempo".

No obstante, nos atrevemos a afirmar que se trata de un deterioro puramente exterior, condicionado en última instancia por el paso del tiempo. Íntimamente, la simbiosis con el joven presenta efectos terapéuticos para el viejo alado. Este echará finalmente a volar, así sea torpemente, poco después de que el niño comience a asistir con normalidad a la escuela, en plena salud.

En La Rue..., Man'Tine, la abuela del infantil narrador-protagonista, si bien no tiene alas, pertenece igualmente al reino de las aves. Nótese que, en el cuento de Márquez, de un corpus de 2,683 palabras en total, las dos más repetidas son 
“ángel” (con 18 ocurrencias) y "alas" (12 ocurrencias) $)^{4}$, como ilustran los siguientes gráficos:

\section{ángel}

4

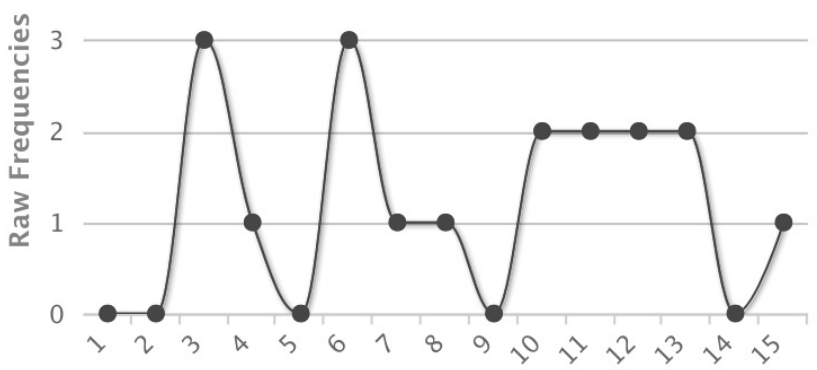

alas

4

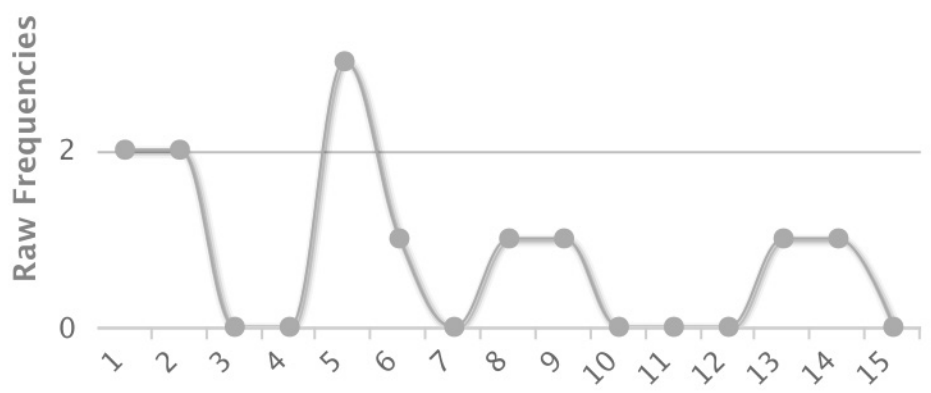

Figs. 1 y 2: "ángel” y "alas": palabras más empleadas en el cuento Un señor muy viejo con unas alas enormes de Gabriel García Márquez. Frecuencia de aparición por segmentos de texto.

Regresando a las alas de Man'Tine, aunque no puedan observarse estadísticamente, dejan sentir su presencia a lo largo de todo el texto. La condición alada de esta abuela adopta en el relato la forma informe, si se nos permite el oxímoron, del humo del tabaco que la rodea en permanencia. Man'Tine acostumbra a fumar en pipa. Este objeto, clásicamente asociado a figuras masculinas / paternales, desencadena cada noche, al atardecer, tras el trabajo inhumano de los esclavos la plantación y el vagabundear salvaje de los niños por los mornes, el compartido ritual de la enso-

$4 \quad$ Análisis estadístico del texto y gráficos obtenidos gracias a la herramienta gratuita en línea Voyant-Reveal Your Texts: SINCLAIR, S.; ROCKWELL, G.: "Voyant Tools: Reveal Your Texts" <http://voyant-tools.org> (Acceso 8 febrero 2016). 
ñación. Niño y anciana, en silencio, el uno junto a la otra -y viceversa- se elevan con el humo en la absorta contemplación del cielo sonoro de la isla, repleto de colibríes, mariposas y luciérnagas que despliegan poco a poco la noche.

Por añadidura, el personaje de la abuela Man'Tine aparece asociado, desde las primeras páginas, al canto: "Man'Tine fredonne une des ces mélopées qui sourdent continuellement de l'habitation, et que je chante parfois aussi" (ZOBEL 1974: 14). Por si todo lo anterior no bastara, Man'Tine se esfuerza cada ocaso en cocinar, lenta y amorosamente, aderezando cada ingrediente con música, un canario en salsa para su nieto: "Certains soirs, je n'aimerais pas rester longtemps à attendre le dîner. J'ai faim et je trouve que Man'Tine chante trop au lieu de regarder si le canari est cuit" (ZOBEL 1974: 14).

El cuerpo marchito del temible ángel Man’Tine no coincide con el cuerpo fértil, en flor, de la madre biológica ausente. Sin embargo, como vemos, será ese cuerpo seco de mujer anciana quien arrulle y quien llame al orden; quien amamante, alimente y asegure el crecimiento saludable en todos los sentidos del infantil narrador-protagonista:

Alors, du corsage de sa robe, elle retirait quelque friandise qu'elle me donnait : une mangue, une goyave, des icaques, un morceau d'igname, reste de son déjeuner, enveloppé dans une feuille verte ; ou, encore, mieux que tout cela, un morceau de pain. M'man Tine me rapportait toujours quelque chose à manger. Ses compagnes de travail en faisaient souvaient la remarque, et m'man Tine disait qu'elle ne pouvait porter quoi que ce soit à sa bouche qu'elle ne m'eût réservé une part (ZOBEL 1974: 9 y 10).

"La question nourriture vient toujours au premier plan de nos préoccupations" (ZOBEL 1974: 21), afirma, erigiéndose en portavoz de su grupo de amigos callejeros, el niño narrador de La Rue... Se suceden a continuación los episodios donde la banda de niños organiza desesperadas batidas por la isla y sus chabolas en pos de frutas maduras o terrones de azúcar: cualquier migaja de dulzura que les permita olvidar la frugalidad de esas comidas que sus progenitores les dejado han más o menos preparadas en la chabola antes de partir, muy temprano, a recoger cañas de azúcar bajo los látigos de los señores blancos o "békés" 5 " en las plantaciones (ZOBEL 1974: 38). Por lo general, la dieta de estas familias se basa en la insípida harina de manioc -un tubérculo local-, las raíces cocidas, las bananas, el arroz, algunas aves pequeñas cazadas literalmente al vuelo y esporádicas porciones de bacalao salado. Las gachas harinosas que mencionamos en primer lugar son consumidas por igual por niños y ancianos de La Rue... Diariamente, en el desayuno, la comida y/o la cena. Abuelos y nietos vuelven a ilustrar la analogía profunda entre las etapas extremas de la existencia humana. El ángel anciano de Márquez, como el bebé enfermo a quien guarda, también se alimentará exclusiva y mecánicamente, por impulso, de "papillas de berenjena".

A la obsesión por la comida que comparten infantes y tercera edad, habría que añadir el afán de transgresión y libertad. Esto es, la rebeldía ante los límites marca-

Término criollo -de connotaciones despectivas- muy empleado en todo el Caribe francófono para referirse a los plantócratas, es decir, a los blancos ricos dueños de plantaciones, con orígenes europeos y no insulares, esclavistas o descendientes de esclavistas. 
dos, ya sea por inconsciencia del paso inexorable del tiempo o bien por un exceso de ella.

Man'Tine trata, así, de transgredir la jerarquía de su mundo de roles genéricos y raciales fumando en pipa y soñando en alto con una soledad que en su fuero interno no desea.

Pelayo y Elisenda pretenden transgredir la bajeza de su clase social usando el dinero ganado a fuerza de exhibir al ángel anciano de su hijo para reformar su casa, comprarse zapatos caros y encargar vestidos de seda que cubran la realidad desnuda de su pobreza original irremediable.

Los niños de La Rue..., por su parte, experimentan su particular sucedáneo de libertad al quedar solos cada día sin sus tutores ancianos. Mientras "les grandes personnes" (ZOBEL 1974: 21) recolectan la caña, los niños apedrean animales, se disputan, hurtan en huertos ajenos, aderezan sus papillas de harina con los pocos lujos que cada cual encuentra en su chabola y comparte con el grupo... Exploran sin inhibiciones los límites del Bien y del Mal, al igual que lo harán los célebres personajes infantiles de Lord of The Flies, de William Golding (1954). Exprimen, en fin, la breve y confusa "liberté ensoleillée" que les brinda la ausencia temporal de los mayores (ZOBEL 1974: 29).

En otras ocasiones, son los ancianos guardianes quienes se permiten fantasear, por breves momentos, con desatender su rol benéfico y recuperar el cómodo egoísmo de la anterior vida en soledad: "Alors, elle [Man'Tine] décide une fois de plus de m'envoyer à Délia, ma mère" (ZOBEL 1974: 42). Mas las dos partes saben bien lo mucho que, en realidad, se necesitan la una a la otra. Conocen la auténtica dimensión de su simbiosis. Sin el bebé y el anciano, caras de una misma moneda, la casa de la pareja protagonista no se vería convertida en centro de peregrinación y espectáculo, cierto. Pero con toda probabilidad tampoco acertaría a mantenerse largo tiempo en pie, cayendo bajo el peso de su propia ruina.

Cuando, en el texto de Zobel, no queda ni una "grande personne à la rue Cases" (ZOBEL 1974: 22), es verdad que los niños viven sin miedo a las represalias y violencias del "monde mystérieux" (ZOBEL 1974: 48) de los adultos. A medida que transcurre el día, sin embargo, los semi-huérfanos de la calle Cases sienten la necesidad de la presencia tranquilizadora de un ángel anciano, tan anciano que ya no trabaje en ninguna plantación y nunca cambie de sitio. Una figura cierta en cualquier circunstancia, a la que acudir sin temor a no encontrarla en caso de urgencia. Una figura, en fin, para ocupar las horas que faltan hasta el regreso crepuscular del resto de adultos. Cada uno de esos niños, así, tiene su viejo preferido en el poblado entre todos los viejos sin descendencia o pupilos del poblado. Cada niño, además, esgrime personales motivos para justificar tal elección:

Romane, c'est Mam'zelle Appoline qu'elle préfère. Une vieille qui n'y voir pas clair, et qui nous appelle pour lui retirer des chiques des pieds, ce que je n'aime pas faire [...]. Tortilla préfère M. Asselin, Asselin-pain. Quelqu'un qui ne fait jamais du feu chez lui. Il n'a pas de femme et ne se nourrit que de pain, de morue salée et de rhum. C'est le nègre le plus robuste de la rue Cases [...]. Moi, mon grand ami ne me donne rien. Il est le plus vieux, le plus misérable, le plus abandonné de toute la plantation. Et je l'aime plus que de courir, gambader, me dissiper ou chiper du sucre [...]. Mais le soir, pendant que je regardais fumer m'man Tine, je ne souhaitais qu'une chose, je n'attendais qu'une chose : que la voix de M. Médouze m'eût appelé (ZOBEL 1974: 50 y 51). 
Para concluir, a la luz de todo lo expuesto y en palabras de Roland Barthes, parece cierto que "la existencia no es una cuestión de fisiología, sino de memoria" (1953: 190). Pues, quienes comienzan el viaje, necesitan, para orientarse, ángeles ancianos que compartan su memoria del camino. Y quienes ya anduvieron todas las sendas y vislumbran la desembocadura del río en el océano, precisan compartir su memoria de la ruta para seguir, de algún modo, navegando después de hundidos.

\section{Referencias bibliográficas y sitográficas}

Amigo, C. (2013). "Inscribir, mostrar y recrear una cicatriz: infancia y escritura en la novela autobiográfica del Caribe". Ais thésis. Dossier : Escrituras de infancia. Sao Paulo: Universidad de Sao Paulo, 54.

Ariès, Ph. (1960). L'enfant et la vie familiale sous l'Ancien Régime. París: Pion.

Barthes, R. (1953). Nouveaux essais critiques. París: Seuil.

Bernabé, J.; Chamoiseau, P.; Confiant, R. (1993). Éloge de la créolité. París: Gallimard.

Carpentier, A. (2004). América, la imagen de una conjunción. Barcelona: Anthropos.

Césaire, A. (1955). Discours sur le colonialisme, suivi du discours sur la Négritude. París: Présence Africaine.

De Beauvoir, S. (1970). La vieillesse. París: Gallimard.

Derrida, J. (1967). L'écriture et la différence. París: Seuil.

García Márquez, G. (2014). Todos los cuentos. Barcelona: Radom House Mondadori.

Golding, W. (2009). El señor de las moscas. Madrid: Alianza.

González, Á. (1956). Áspero mundo. Madrid: RIALP.

Julien, E. (1987). La métamorphose du réel dans «La rue Cases-Nègres». The French Review, 60, 6, 781-787.

Minois, G. (1987). Histoire de la vieillesse en Occident. De l'Antiquité à la Renaissance. París: Bayard.

Pfaff, F. (1996). Conversations with Maryse Condé. Nebraska: University of Nebraska Press.

Úslar Pietri, A. (1948). Letras y hombres de Venezuela. México: Fondo de Cultura Económica.

Zobel, J. (1974). La Rue Cases-Nègres. París: Présence Africaine. 